\title{
EKSISTENSI MASJID DI PERKOTAAN DALAM PENGEMBANGAN PENDIDIKAN AGAMA ISLAM
}

\author{
Prasetio Rumondor ${ }^{1}$, Rohit Manese ${ }^{2}$ \\ Program Pascasarjana, UIN Sunan Kalijaga Yogyakarta \\ e-mail: thiorumondor@gmail.com ${ }^{1}$
}

\begin{abstract}
The condition of the city is marked by the process of modernization that is massive enough to create its own challenges for the mosque in carrying out its role. Muslims in urban areas become particular because they are busy with work that allows little room to go to the mosque. Therefore, the mosque must compete with other public spaces such as luxury buildings that become centers of entertainment, shopping and even become a place of training which is a favorite place for Muslims who live in the city. To develop Islamic religious education in order to attract Muslims to fill mosques. This study aims to determine the role and existence of the Yogyakarta Ash-Shiddiiqi Mosque as well as supporting and inhibiting factors in developing Islamic religious education in the midst of urban globalization. The research method is qualitative descriptive with a case study approach. The results showed that the management of this mosque was very good with the performance of its management until the mosque Ash-Shiddiiqi continued to exist in the midst of urban currents. The function of the mosque from worship is transformed into the surrounding Islamic educational institutions. Islamic education through Ta'lim, monthly recitation, TPA and mosque development as a center of community education activities and greatly assist the Yogyakarta city government in fostering knowledge and morals for the progress of the nation. Aside from that, the findings in the field also show obstacles to the implementation of education with urban conditions where pilgrims are often busy with their work. Nevertheless, the mosque AshShiddiiqi has remained consistent in developing Islamic education in the city of Yogyakarta.
\end{abstract}

Keywords : Development, Islamic Education, the Role and Existence of Mosques 


\section{Abstrak}

Kondisi kota ditandai dengan proses modernisasi yang cukup masif membuat tantangan tersendiri bagi masjid dalam melaksanakan perannya. Umat Islam yang berada di perkotaan menjadi partikularitas karena sibuk dengan pekerjaan yang memungkinkan sedikit ruang gerak untuk ke Masjid. Oleh karena itu, masjid harus bersaing dengan ruang publik yang lain seperti gedung-gedung mewah yang menjadi pusat hiburan, perbelanjaan bahkan menjadi tempat berlangsungnya pelatihan yang menjadi tempat kesayangan bagi umat Islam yang hidup di Kota bukan hanya tempat melaksanakan shalat melainkan masjid harus berupaya untuk mengembangkan pendidikan agama Islam agar dapat menarik umat Islam untuk memenuhi masjid. Penelitian ini bertujuan untuk mengetahui peran dan eksistensi Masjid Ash-Shiddiiqi Yogyakarta serta faktor pendukung dan penghambat dalam mengembangkan pendidikan agama Islam di tengah arus globalisasi perkotaan. Adapun metode penelitian adalah kualitatif deskriptif dengan pendekatan studi kasus. Hasil penelitian menunjukkan bahwa pengelolaan masjid ini sangat bagus dengan kinerja para pengurusnya hingga masjid Ash-Shiddiiqi terus bereksistensi di tengah arus perkotaan. Fungsi masjid dari peribadatan bertransformasi menjadi lembaga pendidikan Islam masyarakat yang berada disekitar. Pendidikan Islam melalui Ta'lim, pengajian bulanan, TPA dan pembinaan masjid sebagai pusat kegiatan pendidikan masyarakat dan sangat membantu pemerintah kota Yogyakarta dalam pembinaan ilmu dan akhlak bagi kemajuan bangsa. Selain dari itu temuan dilapangan juga menunjukan faktor penghambat pelaksanaan pendidikan dengan kondisi perkotaan yang jamaahnya seringkali sibuk dengan pekerjaannya. Meskipun demikian masjid Ash-Shiddiiqi tetap konsisten dalam mengembangkan pendidikan Islam di kota Yogyakarta.

Kata Kunci : Pengembangan, Pendidikan Agama Islam, Peran dan Eksistensi Masjid 
ICIT | Proceding

The First International Conference on Islamic Thought (ICIT)

IAI Al Khairat Pamekasan 18 Januari 2020

\section{PENDAHULUAN}

Secara harfiah masjid merupakan tempat ibadah umat Islam, selain untuk tempat peribadatan masjid menjadi pusat peradaban umat Islam. Dalam kamus besar bahasa Indonesia masjid adalah sebagai rumah atau bangunan tempat bersembahyang bagi orang Islam. ${ }^{1}$ Abdul Malik As-Sa'adi mendefinisikan masjid sebagai tempat yang khusus disiapkan untuk pelaksanaan shalat lima waktu dan berkumpul yang berlaku selamanya. ${ }^{2}$ Quraish Shihab berpendapat bahwa masjid adalah tempat shalat umat Islam, namun akar katanya terkandung makna "tunduk dan patuh", karena itu hakikat masjid adalah tempat melakukan aktivitas "apapun" yang mengandung kepatuhan kepada Allah Swt. ${ }^{3}$ Sedangkan Sidi Gazalba menjelaskan bahwa masjid tempat mengajarkan, membicarakan, menyimpulkan semua pokok kehidupan Islam terperinci pada tiga bidang yaitu agama, antropologi dan kebudayaan, atau istilah dalam ilmu Islam, yaitu ibadah, taqwa dan muamalah. ${ }^{4}$ Sehingga masjid dibangun untuk kebutuhan umat Islam, dalam kebutuhan spiritualitas dan masjid sebagai sarana untuk umat muslim tunduk patuh dan mendekatkan diri kepada Allah Swt. ${ }^{5}$ Bukan hanya itu masjid juga sebagai tempat berlangsungnya pengembangan pendidikan Islam.

Masjid pada zaman Rasulullah didirikan untuk menjadi tempat berdakwah dan pusat ilmu pengetahuan Islam, sebagaimana proses pembelajaran yang sering dilakukan Rasulullah untuk mengenalkan pada bangsa Arab waktu itu. Masjid berfungsi bukan hanya mengikuti pemaknaannya saja sebagai tempat sujud. Berdasarkan pendirian awalnya masjid merupakan pusat kegiatan umat Islam. Sir Thomas Arnold mengatakan dalam buku yang ditulis Hasan Ibrahim Masjid bukan hanya berfungi sebagai tempat ibadah saja, melainkan berfungsi sebagai pusat kegaiatan politik dan sosial. Kegiatan ini dilakukan karena sesuai dengan konteks pada waktu bahwa Rasulullah harus menerapkan politik sebagai tindakan

\footnotetext{
${ }^{1}$ Departemen Pendidikan Nasional, Kamus Besar Bahasa Indonesia (Jakarta: Pusat Bahasa, 2008), 719.

${ }^{2}$ Moh. E. Ayub, Manajemen Masjid: Petunjuk Praktis Bagi Para Pengurus (Jakarta: Gema Insani Press, 1996), 2.

${ }^{3}$ Nurkholish Madjid, Masyarakat Membumikan Nilai-Nilai Islam Dalam Kehidupan Masyaraskat (Jakarta: Paramadina, 2004), 98-99.

${ }^{4}$ Sidi Gazalba, Mesjid Pusat Ibadah Dan Kebudayaan (Jakarta: Pustaka Antara, 1962), 120.

${ }^{5}$ Ahmad Putra and Prasetio Rumondor, "Eksistensi Masjid Di Era Rasulullah Dan Era Millenial," TASÂMUH 17, no. 1 (December 31, 2019): 247.
} 
dakwah agar umat Islam bisa diterima dan melawan para penguasa dan pengusaha yang dzalim pada waktu itu. Dari kegiatan ini masjid menjadi sarana Transfer of Knowledge, sebagaimana dalam berpolitik Rasulullah mengajarkan kepada umatnya dan disitulah proses pembelajaran berlangsung.

Selain itu masjid bukan hanya sebagai tempat menyampaikan syiar saja, tempat mengagungkan Allah, tempat menyampaikan shalawat kepada nabi, tempat memohon rahmat bagi sahabat, tempat melantik para pejabat baru, atau tempat berlangsungnya pernikahan. Namun masjid juga mempunyai fungsi yang lain yakni sebagai tempat persinggahan bagi para musafir maupun bagi khalayak umum. Dalam hal pendidikan masjid sangat relevan ketika dijadikan sebagai lembaga pendidikan. Dalam Masjid akan hidupnya kewajiban manusia sebagai seorang Islam menjalankan perintah Allah lewat Al-qur'an dan Hadis, serta menghilangkan stratifikasi manusia dan status ekonomi serta status pendidikannya. Di lihat dari berbagai definisi dan pengistilahan di atas peran masjid sangat penting dalam kehidupan umat Muslim. Masjid bukan sekedar tempat berlangsungya ritual, namun menjadi pusat perdaban Islam.

Masjid memegang peranan penting dalam penyelenggaraan pendidikan Islam dalam masyararakat, maka dari itu masjid merupakan lembaga yang sangat penting peranannya dalam pengembangan masyarakat. Pendidikan Islam yang merupakan pengkondisian dari syarat berkembangya masyarakat. Untuk itu dalam mengetahui pengembangan pendidikan Islam. Penulis menganalisa pendidikan Islam secara teori terlebih dahulu. H. M. Arifin mengatakan bahwa Pendidikan Islam diartikan sebagai rangkaian usaha membimbing, mengarahkan potensi hidup manusia yang berupa kemampuan-kemampuan dasar dan kemampuan belajar, sehingga terjadilah perubahan di dalam kehidupan pribadinya sebagai makhluk individual dan sosial serta dalam hubungannya dengan alam sekitarnya dimana ia hidup. Proses tersebut senantiasa berada di dalam nilai-nilai yang melahirkan norma-norma syariah dan akhlaq al-karima. ${ }^{6}$ Al-Gazali mendefinisikan pendidikan adalah proses memanusiakan manusia sejak masa kejadiannya sampai akhir hayatnya melalui beragam ilmu pengetahuan yang disampaikan dalam bentuk pengajaran secara bertahap proses pengajaran itu

\footnotetext{
${ }^{6}$ H. M. Arifin, Filsafat Pendidikan Islam (Jakarta: Bumi Aksara, 1994), 11.
} 
ICIT | Proceding

The First International Conference on Islamic Thought (ICIT)

IAI Al Khairat Pamekasan 18 Januari 2020

menjadi tanggung jawab orang tua dan masyarakat menuju pendekatan diri kepada Allah Swt. sehingga menjadi manusia yang sempurna. ${ }^{7}$ Zakiyah Daradjat mendefinisikan pendidikan Islam sebagai suatu usaha untuk membina dan mengasuh peserta didik agar senantiasa dapat memahami ajaran Islam secara menyeluruh serta menghayati tujuan, yang pada akhirnya dapat mengamalkan dan menjadikan Islam sebagai pandangan hidup. ${ }^{8}$ Abuddin Nata mengatakan bahwa pendidikan Islam adalah kegiatan pengajaran dapat dihasilkan manusia yang pandai dan berwawasan luas sebagai dasar dalam mengambil keputusan melalui kegaiatan pendidikan dapat dihasilkan manusia yang berkepribadian utama, berakhlak mulia, berpegang teguh pada nilai nilai yang ideal dan utama. ${ }^{9}$

Maka berangkat dari ketiga pendapat diatas pendidikan Islam adalah usaha sadar yang dilakukan melalui kegiatan, pembelajaran, bimbingan dan pelatihan seluruh aktifitas yang dilatarai oleh hasrat untuk menggali nilai-nilai Islam. Dalam definisi ini antara pengembangan dan peranan masjid hubungannya terdapat dalam praktik pendidikannya (realisasi) dan masjid dari fungsi ibadah bertransformasi menjadi pusat pendidikan non-formal. Dalam hal praktik pendidikannya maka yang dilakukan masjid sebagai lembaga pendidikan Islam adalah Pengajian, Taklim, pembinaan remaja masjid, dan sebagai Taman Pengajian Al-qur'an tak lupa pendidikan Islam tidak ada pendikotomian dengan pendidikan secara umum. Artinya dalam pengembangan pendidikan di masjid, ilmu tidak dibatasi oleh ilmu agama ada ilmu umum yang diajarkan untuk menambah wawasan dari jamaah masjid agar tidak terekslusi dari keilmuan secara umum. Dan dari transformasi masjid. Masjid bukan hanya sebagai tempat berlangsungya peribadatan atau hanya sebagai tempat sujud. Tapi masjid menjadi penyelenggara pendidikan yang berada dimasyarakat karena kemajuan masyarakat ditentukan oleh pendidikannya. Dari kegiatan-kegiatan tersebut maka pendidikan yang tersebut terlaksana dalam pendidikan keagamaan sebagai landasan moral masyarakat hidup diperkotaan. Terciptanya landasan moral dari masyarakat tersebut maka membuktikan keberhasilan peran masjid bukan dilihat dari ukuran

${ }^{7}$ Abidin Ibnu Rusn, Pemikiran Al-Ghazali Tentang Pendidikan (Yogyakarta: Pustaka Pelajar, 2009), 56.

8 Abdul Madjid, Pendidikan Agama Islam Berbasis Kompetensi: Konsep Dan Implementasi Kurikulum 2004 (Bandung: PT Remaja Rosadakarya, 2005), 130.

${ }^{9}$ Abuddin Nata, Pendidikan Dalam Perspektif Al-Qur'an (Jakarta: Kencana, 2016), 101. 
fisiknya tapi dari pengelolaannya terhadap jamaah sebagai sumber daya manusia. Dengan pengembangan pendidikan Islam ini secara praktis maka masjid mempertahankan eksistensinya di tengah perkotaan yang memiliki keanekaragamannya permasalahannya maka pendidikan Islam di masjid menjadi jawaban atas segala permasalahan tersebut

Masjid-masjid di Indonesia memiliki kesamaan dengan fungsi masjid yang digambarkan pada masa Rasulullah, keberadaannya di tengah kehidupan masyarakat bukan hanya sebagai tempat pelaksanaan Ibadah semata tetapi juga berfungsi sebagai pusat kegiatan masyarakat seperti tempat berlangsungya proses pembelajaran (pendidikan), perkawinan, goton royong masyarakat dan tempat berlangsungnya kegiatan keagamaan seperti peringatan hari besar Islam. Di daerah perkotaan masjid berfungsi sebagai tempat Ibadah selain dari pada itu berfungsi sebagai tempat belajar seperti madrasah diniyyah, pusat diskusi dan kajian keagamaan bagi masyarakat setempat dan khalayak umum, pembinaan generasi muda Islam dan lain-lain. Maka untuk memperjelas mengenai peran masjid yakni penulis menarik benang merahnya bahwa masjid sebagai tempat peribadatan, masjid sebagai lembaga dakwah, masjid sebagai lembaga kemasyarakatan dan masjid sebagai tempat pengembangan pendidikan. Dari hal tersebut salah satu masjid yang ada di kota Yogyakarta yaitu Masjid AshShiddiiqi dituntut untuk terus mengembangkan pendidikan agama Islam, karena posisinya sangat strategis.

Bila kita melihat disekitar Masjid Ash-Shiddiiqi posisinya sungguh strategis diantaranya masjid berada di keramaian Kota Yogyakarta yang beralamat di Kelurahan Demangan Kec. Gondokusuman tepatnya Demangan Kidul GK I/51 RW 05 RT 16 Yogyakarta. Di sebelah utara berdekatan dengan pusat perbelanjaan LIPPO Mall, sebelah selatan berdekatan dengan Kantor Kelurahan Demangan dan Kantor Kec. Gondokusuman, kampus LPP dan IST Akprind, sebelah barat berdekatan dengan Hotel Sala, Pom Bensin Jl. Munggur, Kantor Pos Kecamatan Gondokusuman, dan sebelah timur berdekatan dengan Pusat Kursus Bahasa Asing 
ICIT | Proceding

The First International Conference on Islamic Thought (ICIT)

IAI Al Khairat Pamekasan 18 Januari 2020

\& Komputer (JCC), dan kampus UIN Sunan Kalijaga. Masjid tersebut memiliki konsep arsitektur yaitu tropis kontemporer. ${ }^{10}$

Konsep arsitektur masjid Ash-Shiddiiqi memadukan prinsip-prinsip arsitektur tropis dengan bahasa kontemporer dalam desain masjid. Penggunaan konsep ini memungkinkan untuk menyelesaikan permasalahan-permasalahan yang ada seperti luasan lahan yang sangat terbatas dan luas fungsional bangunan yang besar, bangunan sekitar dengan tinggi 1-2 lantai; serta kebutuhan udara dan cahaya (tanpa konsumsi energi yang besar) dengan lebih banyak alternatif. Konsep tropis kontemporer ini juga dipandang sesuai dengan kultur sosial masyarakat sekitar yang sangat heterogen dan berkarakter urban. ${ }^{11}$

Melihat kondisi tersebut mulai dari posisi masjid yang strategis dan gaya arsitekturnya yang bagus sehingga menarik jamaah, namun masjid yang ada di perkotaan harus ditransformasikan perannya bukan hanya sebagai tempat ritual semata namun sebagai tempat pengembangan pendidikan agama Islam. Pengembangan tersebut untuk upaya agar menambah kuantitas jamaah masjid dan pusat kegiatan keilmuan masyarakat, pengembangan ini menjadikan masjid sebagai basis pusat peradaban jamaah dan menjawab tantangan modernitas. Pendidikan agama Islam di masjid bukan hanya sebagai tempat elaborasi keilmuan semata namun ada penanaman Akhlak sebagai basis moral yang dimiliki oleh umat Islam.

Riset yang difokuskan mengenai eksistensi masjid telah banyak dilakukan, diantaranya dilakukan oleh Prasetio dan Putra dalam eksistensi masjid di era Rasulullah dan di era milenial yang menemukan tentang keberfungsian masjid sebagai tempat dilaksanakannya kegiatan-kegiatan keagamaan di era Rasulullah maupun di era Millenial. ${ }^{12}$ Penelitian yang dilakukan oleh Rasyid dan Amirullah juga menemukan bahwa masjid Makmur Melayu dapat mempengaruhi masyarakat Makassar yang berada disekitarnya karena masjid menjadi pusat

10 Admin, Sejarah Masjid, https://masjidashshiddiiqi.wordpress.com/sejarah/\#more-3 (accessed January 2, 2020).

${ }^{11}$ Harry Kurniawan, Karya Desain Masjid Ash-Shiddiqqi Yogyakarta, 2015, 4.

${ }^{12}$ Putra and Rumondor, "Eksistensi Masjid Di Era Rasulullah Dan Era Millenial." 
aktivitas yang berkaitan dengan sisi keagamaan maupun sosial. ${ }^{13}$ Penelitian yang dilakukan oleh Dalmeri yang menemukan bahwa masjid sebagai pusat ekonomi dan dakwah multikultural terhadap masyarakat, pemberdayaan ini sebagai dakwah sosial bagi komunitas miskin disekitar masjid. ${ }^{14}$ Hal tersebut juga berkaitan dengan penelitian dari Subhan mengenai fungsi Masjid Agung terhadap alun-alun kota Malang yang menemukan bahwa masjid sebagai pusat pemerintahan, pendopo dan masjid yang mengatur tentang ekonomi masyarakat dan sebagai tempat keagamaan sehingga masjid Agung kota Malang sangat memilik peran dalam perkembangan alun-alun kota Malang. ${ }^{15}$

Disisi lain masjid bukan hanya sebagai pusat pemerintahan, keagamaan, ekonomi yang dilakukan dari masa Rasulullah hingga sekarang namun juga sebagai tempat berlangsungnya pendidikan. Hal tersebut bisa dilihat dalam penelitian Iqbailah tentang peran masjid agung Jami' Malang dalam pembinaan agama Islam anak yatim piatu non panti di kota Malang melalui Madrasah Diniyah Abul Yatama yang menemukan bahwa pembinaan terhadap anak yatim piatu melalui Madrasah Diniyah Abul Yatama dilakukan melalui peribadatan, pendidikan dan sosial. ${ }^{16}$ Sama halnya dengan penelitian Prasetio dan Puspasari yang menemukan bahwa masjid sebagai tempat pendidikan remaja dalam pembinaan kepribadian dan keagamaan. ${ }^{17}$

Maka dari itu masjid dalam mempertahankan eksistensinya dalam arus perkotaan serta sebagai pusat kegiatan umat. Masjid harus direvitalisasi terus menerus agar bisa berpengaruh bagi kehidupan masyarakat sekitarnya.

Penelitian ini memperkaya penelitian-penelitian sebelumnya mengenai peran maupun fungsi masjid diperkotaan maupun di era milenial. Namun

\footnotetext{
${ }^{13}$ M. Rasyid Ridha and Amirullah Amirullah, "Eksistensi Masjid Makmur Melayu Dalam Syiar Islam Di Kota Makassar (1943-2015)," Seminar Nasional LP2M UNM 2, no. 1 (October 7 , 2017): 457-461.

${ }^{14}$ Dalmeri Dalmeri, "Revitalisasi Fungsi Masjid Sebagai Pusat Ekonomi dan Dakwah Multikultural," Walisongo: Jurnal Penelitian Sosial Keagamaan 22, no. 2 (December 15, 2014): $321-350$.

15 Subhan Ramdlani, "Kedudukan Dan Fungsi Masjid Agung Terhadap Alun-Alun Kota Malang," Journal of Islamic Architecture 1, no. 1 (March 29, 2010): 8-15.

${ }^{16}$ Muhammad Iqbalillah, "Peran Masjid Agung Jami' Malang Dalam Pembinaan Agama Islam Anak Yatim Piatu Non-Panti Kota Malang Melalui Madrasah Diniyah Abul Yatama" (Skipsi, Fakultas Ilmu Tarbiyah dan Keguruan UIN Maulana Malik Ibrahim Malang, 2014).

${ }_{17}$ Prasetio Rumondor and Puspasari M. Y. Gobel, "Pola Pembinaan Kepribadian dan Keagamaan Remaja Masjid Al-Fatah Di Kelurahan Girian Indah Kecamatan Girian Kota Bitung," Al-Izzah: Jurnal Hasil-Hasil Penelitian 14, no. 2 (December 14, 2019): 1-16.
} 
ICIT $\mid$ Proceding

The First International Conference on Islamic Thought (ICIT)

IAI Al Khairat Pamekasan 18 Januari 2020

bagaimanapun penelitian ini memilik perbedaan dengan penelitian sebelumnya. Di mana dalam mempertahankan eksistensi masjid di perkotaan, masjid AshShiddiiqi ini memilih melalui pengembangan pendidikan Islam inisaitif ini diambil oleh pengurus masjid karena pendidikan sangat penting untuk kehidupan jamaahnya dan dari pengembangan pendidikan Islam yang dilakukan masjid AshShiddiiqi menjadi pusat pendidikan informal yang berada di kota Yogyakarta. Penelitian ini bertujuan untuk mengetahui peran dan eksistensi Masjid AshShiddiiqi Yogyakarta serta faktor pendukung dan penghambat dalam mengembangkan pendidikan agama Islam di tengah arus globalisasi perkotaan.

\section{METODE PENELITIAN}

Penelitian ini merupakan penelitian kualitatif karena model analisa yang digunakan bersifat deskriptif diharapkan akan menjadi sebuah paparan yang ringan dan sekaligus dapat menarik fakta yang ada di lapangan untuk diuraikan secara mendalam. Penelitian ini dilaksanakan di Masjid Ash-Shiddiiqi Demangan kota Yogyakarta. Dengan pertimbangan masjid tersebut memiliki karakteristik tertentu sesuai dengan permasalahan yang diteliti.

Jenis penelitian ini menggunakan studi kasus. Jenis ini dapat di identifikasi dalam 3 luaran yang dihasilkan, yaitu 1) dapat mengeksplorasi kasus secara lebih mendalam berdasarkan data-data yang akurat, 2) mendskripsikan hasil ebih rinci sehingga mudaj untuk dimengeri orang lain, dan 3) dapat dijadikan sebaga jalan untuk menguji teori. $^{18}$

Subyek penelitian ini adalah pengurus Badan Takmir Masjid dan marbot masjid yang memiliki status sebagai mahasiswa UIN Sunan Kalijaga Yogyakarta yang juga bersentuhan dengan pengelolaan masjid. Pengumpulan data dilakukan dengan tiga metode yaitu wawancara, observasi, dokumentasi. Dari hasil pengumpulan data penulis melanjutkan dengan menganalisa data secara deskriptif agar penelitian ini tersusun secara sistematis dan dapat dipahami serta tersusun sesuai dengan hasil wawancara. 2011), 86 .

${ }^{18}$ Robert K. Yin, Qualitative Research from Start to Finish (London: The Guilford Press, 


\section{Optimalisasi Peran Masjid Ash-Shiddiiqi sebagai Sarana Pendidikan}

Optimalisasi adalah penyederhanaan dari kata optimal yang mempunyai arti paling bagus, tetinggi, terbagus dan paling menguntungkan. Sehingga optimalisasi berarti pengelolaan yang sesuai dan pas terhadap apa yang ada. Maka dalam arti yang luas yaitu bagaimana masjid, lembaga atau yayasan mengelola sesuatu dengan baik. Hal tersebut dapat dilihat dari manajemen Masjid AshShiddiiqi yang sudah baik dimana pengelolaannya dikelola oleh pengurus Badan Ta'mir Masjid, sebagaimana dengan masjid pada umumnya sehingga dalam pengelolaannya dapat mengorganisasikan dan memajemeni dengan efektif dan efisien.

BTM Masjid dalam kepengurusannya membentuk bidang-bidang sebagai penanggungjawab. Bidang-bidang diantaranya Rumah Tangga, Sarana dan Prasarana, Ibadah dan Pendidikan dan Pengajaran. ${ }^{19}$

Bidang rumah tangga mengurusi kesekretariatan serta unsur pembantu sekretaris BTM untuk mengurusi administrasi masjid. Masjid juga sebagai lembaga yang diorganisasikan harus menata administrasinya dengan baik hal ini untuk pelaporan kepada jamaah nantinya. Sarana dan prasarana yang mengurusi segala urusan fasilitas yang berada di Masjid Ash-Shiddiiqi. Sementara itu, bidang ibadah yang mengurusi urusan peribadatan baik ibadah sholat 5 waktu, sholat Jum'at dan Ta'lim. Bidang pendidikan dan pengajaran mengelola TPA.

Dewasa ini banyak masjid yang sudah dikelola secara professional seperti halnya Masjid Ash-Shiddiiqi. Masyarakat pun sudah merasakan langsung manfaatnya. Adapun masjid-masjid yang telah dikelola secara professional Antara lain, Masjid Al-Azhar yang dikelola oleh Yayasan Pesantren Islam al-Izhar. Masjid tersebut telah diberdayakan dengan mendirikan sekolah-sekolah TK, SD, SMA, dan universitas Al-Azhar yang dipercaya oleh masyarakat karena kualitasnya. Selain mengembangkan pendidikan, masjid ini juga membangun ruang-ruang usaha di sekelilingnya, seperti ruang pertemuan, warung

\footnotetext{
${ }^{19}$ Abdurahman, S.HI Pengurus Badan Ta'mir, wawancara pada Sabtu 4 Januari 2020
} 
ICIT | Proceding

The First International Conference on Islamic Thought (ICIT)

IAI Al Khairat Pamekasan 18 Januari 2020

telekomunikasi, hingga biro perjalanan. Pemberdayaan masjid lainnya seperti Masjid Isqiqomah di Banding dan Masjid Salman ITB. ${ }^{20}$

\section{Program-Program Masjid Ash-Shiddiiqi}

Program yang telah direncanakan di Masjid Ash-Shiddiiqi adalah program peribadatan yakni masjid berdasarkan fungsinya sebagai tempat ibadahnya umat Islam. Perlu diketahui dalam program ini dibawahi oleh bidang Ibadah. ${ }^{21}$ Dalam mengoptimalkan pelaksanaan sholat 5 waktu dan sholat Jum'at dengan melakukan penjadwalan untuk tugas Mu'azin, Khotib hingga Imam. Fungsi ini berdasarkan masjid pada umumnya sejak zaman rasulullah hingga zaman sekarang. Temuan tersebut menunjukkan bahwa masjid sebagai tempat beribadah. Sesuai dengan namanya Masjid adalah tempat sujud, maka fungsi utamanya adalah sebagai tempat ibadah shalat dan beribadah secara luas sesudai dengan ajaran Islam. ${ }^{22}$

Selain dari fungsi diatas, program yang dilaksanakan mengenai pendidikan Islam yakni melalui Taklim. Kajian tersebut merupakan agenda rutinitas mingguan pada hari Selasa Ba'da Maghrib dan pada hari Sabtu Ba'da Subuh. Adapun materi khusus dalam kajian ini meliputi kajian tafsir, fiqh, Kitab, hadis serta dengan tema-tema Islam pada umumnya. ${ }^{23}$ Program lainnya, setiap bulannya Masjid Ash-Shiddiiqi sering membuat acara pengajian yang cukup besar.

Sementara itu, Masjid Ash-Shiddiiqi juga telah menyediakan pendidikan informal lainnya sebagai pusat masyarakat Islam yang berada di Demangan Kidul. Seperti taman pengajian anak-anak (TPA) yang dalam pengelolaannya TPA ini mempunyai direktur hal ini dibuat karena dalam pengelolaan TPA harus ada yang bertanggung jawab.

TPA ini untuk mengajarkan pengajian serta mengenai pengetahuan tentang keislaman. Para murid yang berada di TPA ini selain anak-anak yang merupakan anak-anak dari jamaah masjid, ada juga anak-anak yang datang belajar dari luar jamaah yang berada di Demangan Kidul, peserta yang menjadi murid di TPA ini tiap memasuki ajaran baru selalu bertambah. Para pendidik yang mengajar,

\footnotetext{
${ }^{20}$ Afiful Ikhwan, "Optimalisasi Peran Masjid Dalam Pendidikan Anak: Perspektif Makro Dan Mikro,” Edukasi 1, no. 1 (June 2013): 13.

${ }^{21}$ Abdurahman S.HI Pengurus Badan Ta'mir, wawancara pada Sabtu 4 Januari 2020

${ }^{22}$ Gazalba, Mesjid Pusat Ibadah Dan Kebudayaan, 195.

${ }^{23}$ Luqman Marbot Masjid, Wawancara pada hari rabu 25 Desember 2019
} 
membina dan mendidik di TPA ini adalah para mahasiswa yang memiliki kemampuan dalam hal tersebut. ${ }^{24}$

TPA yang ada di Masjid Ash-Shiddiiqi dibagi menjadi tiga klasifikasi yakni TPA (Taman Pendidikan Al-Qur'an), TKA (Taman Kanak-kanak AlQur'an), TQA (Ta'limul Qur'an Lil Aulad). TKA untuk taman kanak-kanal alQur'an untuk murid yang baru masuk dan masih pada tahap Iqra' 1-3. Taman pendidikan al-Qur'an untuk TPA untuk yang sudah memasuki Iqra' 4, 5, dan 6. dan Ta'limul Qur'an Lil Aulad untuk murid yang sudah memasuki pada tahap alQur'an. Ustad dan ustazah yang mendidik di sini adalah mereka para mahasiswa yang masuk dalam pengurus masjid maupun mahasiswa yang mendaftarkan diri untuk menjadi pendidik.

Dengan adanya TPA yang ada di Masjid Ash-Shiddiiqi yang merupakan program kerjanya. Hal tersebut membuat masjid Masjid Ash-Shiddiiqi mendukung pemerintah Yogyakarta, di dalam Perbaikan akhlak pada generasi penerus yang mempunyai pengaruh besar bagi kejayaan bangsa, sebab suatu bangsa atau Negara akan jaya, apabila warga negaranya terdiri dari orang yang berakhlak luhur dan sebaliknya. ${ }^{25}$

Akhlak yang luhur ini diperoleh apabila sejak kanak-kanak telah ditanamakan lima kekuatan yaitu 1) quwwatul aqidah (keimanan), 2) quwwatul ilm (Ilmu pengetahuan dan teknologi), 3) quwwatul iqtishodi (ekonomi), 4) quwwatul ijtima'i (persatuan dan kesatuan) dan 5) quwwatul khuluqi (kekuatan moral). Sarana strategis untuk menanamkan lima kekuatan tersebut adalah melalui pendidikan dan pengajaran al-Qur'an. ${ }^{26}$ Bila generasi mendatang berpegang teguh dengan al-Qur'an maka dijamin oleh Allah mereka tidak akan tersesat. Hal tersebut sejalan dengan al-Qur'an Surah Al-Isra' ayat 9 berikut:
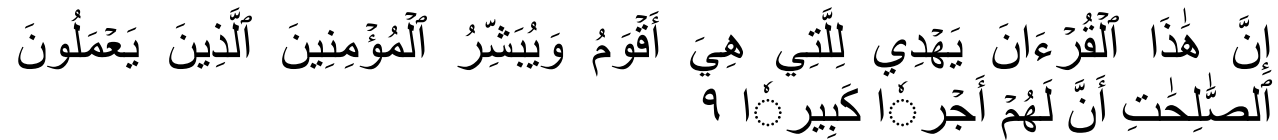

Terjemahnya:

${ }^{24}$ Abdurahman, S.HI Pengurus Badan Ta'mir, wawancara pada Sabtu 4 Januari 2020

${ }^{25}$ M. Ali Hasan, Tuntutan Akhlak (Jakarta: Bulan Bintang, 1983), 8.

${ }^{26}$ M. Budiyanti, Reaktualisasi Khittoh Perjuangan Ustadz-Ustadzah TKA-TPA Dalam Gerakan Dakwah Dan Pendidikan Al-Qur'an Di Indonesia (Yogyakarta: BADKO TKA-TPA Kab Bantul, 2006), 7. 
"Sesungguhnya Al Quran ini memberikan petunjuk kepada (jalan) yang lebih lurus dan memberi khabar gembira kepada orang-orang Mu'min yang mengerjakan amal saleh bahwa bagi mereka ada pahala yang besar."

Sebaliknya, bila suatu generasi tidak lagi berpengang pada al-Qur'an, maka kesesatanpun segera mengancam. Oleh karenanya, pendidikan serta pembinaan akhlak bagi generasi muda secara bijak dapat dilakukan dengan memberikan contoh teladan yang baik dalam kehidupan sehari hari. Segala tindakan generasi muda merupakan penerus bangsa yang beriman dan bertaqwa kepada Allah, SWT, oleh karena itu generasi muda terus mampu mencerminkan diri pribadi, memilik akhlaq mulia dan tauladan yang baik agar dapat mengayomi dan membina kaum muslimin lainnya. ${ }^{27}$

Selain dalam pembinaan remaja masjid. BTM Masjid Ash-Shiddiiqi sering membuat agenda latihan kepemimpinan bagi remaja Masjid Ash-Shiddiiqi secara rutinitas setiap bulan 1 kali. Masjid juga menjadi pusat kegiatan Islami bagi remaja yang berada di sekitaran Demangan Kidul. Hal tersebut sejalan dengan pemikirannya Sidi Gazalba bahwa masjid haruslah menjadi tempat kaderisasi umat dan tempat pembinaan jama'ah dan kepemimpinan umat. Dengan begitu, masjid memerlukan aktivis yang berjuang menegakkan Islam secara Istiqamah dan berkesinambungan. ${ }^{28}$

Para Mubalig masjid yang sering mengisi taklim dimanfaakan sumber daya yang ada diantara jamaah masjid. Sejauh ini progress masjid dalam melaksanakan programnya terutama pendidikan Islam, telah membentuk kesadaran masyarakat sekitar. ${ }^{29}$ Kesadarannya dapat terukur dengan bertambahnya peserta didik yang berda di TPA selain dari itu masjid menjadi pusat pendidikan Taklim sebagai salah satu unsur yang masuk dalam pendidikan keagamaan non-formal disetiap agendanya jamaah yang selalu mengikuti sangat banyak. Masjid ini juga menjadi pusat pendidikan non-formal tercatat beberapa kali mahasiswa Islam menjadikan masjid ini sebagai tempat berlangsungnya

\footnotetext{
${ }^{27}$ Husniah, "Peranan Mesjid Dalam Pembinaan Pendidikan Agama Islam Generasi Muda Di Kecamatan Langsa Barat," Prosiding Seminar Nasional Tahunan Fakultas Ilmu Sosial Universitas Negeri Medan Tahun 2017 1, no. 1 (2017): 214.

${ }^{28}$ Gazalba, Mesjid Pusat Ibadah Dan Kebudayaan, 144.

${ }^{29}$ Abdurahman, S.HI Pengurus Badan Ta'mir, wawancara pada Sabtu 4 Januari 2020
} 
pengajian maupun perkaderan Islami dengan melibatkan para pengurus masjid sebagai pemateri.

Oleh karena itu, masjid bukan hanya tempat ritual ibadah semata melainkan sebagai tempat menuntut ilmu. Supriadi dan Amruddin mengungkapkan bahwa pendidikan Islam termasuk sebagaimana kegitan memakmurkan masjid dan ini sesuai dengan prinsip yang diyakini oleh umat Islam bahwa ilmu itu datangnya dari Allah karena itu masjid lebih utama sebagai tempat menuntut ilmu. ${ }^{30}$

\section{Peranan Masjid dalam Perkotaan}

Melihat posisi Masjid Ash-Shiddiiqi yang strategis. Masjid Ash-Shiddiiqi adalah masjid yang terletak di kelurahan Demangan, Kecamatan Gondoksuman tepatnya Demangan Kidul GK I/51 RW 05 RT 16 Yogyakarta. Masjid yang tidak terlalu besar ini berada di tengah keramaian kota hal ini bisa terlihat pada sebelah bahwa LIPPO Mall, sebelah selatan berdekatan dengan Kantor Kelurahan Demangan dan Kantor Kec. Gondokusuman, kampus LPP dan IST Akprind, sebelah barat berdekatan dengan Hotel Sala, Pom Bensin Jl. Munggur, Kantor Pos Kecamatan Gondokusuman, dan sebelah timur berdekatan dengan Pusat Kursus Bahasa Asing \& Komputer (JCC), dan kampus UIN Sunan Kalijaga. Namun masjid ini tetap eksis menjadi pusat kegiatan bukan hanya para masyarakat Demangan namun mereka yang bekerja di hotel, mall maupun para mahasiswa. Eksisnya masjid lewat program-program tersebut, untuk hal yang lain yakni fasilitas masjid berupa Wi-Fi. ${ }^{31}$ Sementara arsitektur Masjid Ash-Shiddiiqi yang mempunyai struktur bangunan tropis kontemporer sangat sesuai dengan kondisi Yogyakarta dan mendukung. Selain itu Masjid Ash-Shiddiiqi ini diajak bekerjasama dengan rumah sakit Siloam yang berada di sisi Utara masjid. Kerjasama ini untuk membina Rohani Islam di rumah sakit Siloam.

${ }^{30}$ Supardi and Teuku Amiruddin, Supardi Dan Teuku Amiruddin, Manajemen Masjid Dalam Pembangunan Masyarakat Optimalisasi Perdan Dan Fungsi Masjid (Yogyakarta: UII Press, 2001), 133.

${ }^{31}$ Luqman Marbot Masjid, Wawancara pada hari rabu 25 Desember 2019 
ICIT | Proceding

The First International Conference on Islamic Thought (ICIT)

IAI Al Khairat Pamekasan 18 Januari 2020

Faktor Pendukung dan Penghambat Masjid Ash-Shiddiiqi dalam Pengembangan Pendidikan Agama Islam

Faktor pendukungnya terlihat dari antusiasme jamaah yang selalu memiliki niat dan tindakan untuk membangun masjid ini bukan hanya secara fisik namun secara pengelolaan sumber daya manusianya dan masjid juga di dukung oleh Lippo beberapa kali mall tersebut menyumbangkan hewan Qurban pada setiap perayaan hari raya Idul Adha. ${ }^{32}$ Bila kita mengamati Masjid Ash-Shiddiiqi bahwa keamanan dan kebersihan masjid tetap terjaga. Beberapa hansip diarahkan untuk mengamankan masjid ketika sedang melaksanakan program-programnya. Pendukung lainnya, fasilitas masjid berupa ruangan dan alat sarana prasarana pengajaran, selain itu juga adanya pengajar di TPA yg memiliki kualitas profesional. $^{33}$ Sehingga peranan pengajar sangat penting dalam pembentukan generasi Qur'ani, pengajar sebagai orang yang mengajarkan baca tulis al-Qur'an, pengetahuan agama, dan amalan-amalan ibadah yang dapat dilaksanakan oleh anak-anak haruslah mempunyai ilmu pengetahuan yang memadai. ${ }^{34}$ Maka dari itu, pengajar haruslah berkualitas sehingga membentuk penerus bangsa yang berakhlak, berilmu dan penghafal al-Qur'an.

Faktor penghambatnya merupakan dari kondisi perkotaan itu sendiri. Misalnya program-program masjid harus fleksibel dengan kesibukan jamaahnya. Meski begitu tidak pernah ada program yang tertunda. Posisi geografis masjid pun menjadi salah satu hambatan dengan kecilnya tempat parkir seringkali kendaraan yang diparkir tidak beraturan. Disisi lain, dari lingkungan masyarakat sekitar dan muridnya yang terbatas, biasanya murid yang sudah di kelas 3 tidak lagi hadir di TPA karena sekolah mereka yang sudah full day. ${ }^{35}$

\section{PENUTUP}

Berdasarkan uraian di atas kesimpulan ini kami mensistensiskan antara hasil penelitian dan pembahasan yang kami bahas. Masjid Ash-Shiddiiqi adalah masjid yang posisinya terletak di tengah-tengah bangunan perkotaan. Bangunan-

\footnotetext{
${ }^{32}$ Abdurahman S.HI Pengurus Badan Ta'mir, wawancara pada Sabtu 4 Januari 2020

${ }^{33}$ Lalu Rudy Marbot Masjid, wawancara pada Sabtu 4 Januari 2020

34 Siti Nurjannah, Peranan TKA-TPA Dalam Membentuk Keluarga Sakinah Dalam Buletin GEMA Edisi I (Yogyakarta: BADKO TKA-TPA Propinsi DIY, 1997), 6.

${ }^{35}$ Lalu Rudy Marbot Masjid, wawancara pada Sabtu 4 Januari 2020
} 
bangunan tersebut menjadi pusat kegiatan dari masyarakat yang berada di sekitar masjid. Namun dengan adanya program-program yang dilaksanakan masjid ini menjadi pusat masyarakat sebagai jamaah masjid bahkan ada masyarakat yang dari luar. Pengembangan pendidikan Islam masjid dikondisikan dengan adanya pendidikan sebagai praktik. Yakni terlakasnayan proses pendidikan lewat TPA dan kondisi yang berikut adalah transformasi masjid Ash-Shiddiiqi dari tempat peribadatan menjadi pusat kegiatan masyarakat seperti taklim dan pembinaan remaja masjid. Oleh karena itulah masjid berfungsi sebagai pusat ilmu pengetahuan Masyarakat. Dengan program TPA yang dilaksanakan selain mengembangkan masyarakat Islam serta menjadi jawaban atas setiap masalah perkotaan. Masjid Ash-Shiddiiqi yang terletak di kota Yogyakarta ini mendukung pemerintah Yogyakarta, di dalam Perbaikan akhlak pada generasi penerus yang mempunyai pengaruh besar bagi kejayaan bangsa.

Program yang dilaksanakan ukurannya adalah terbangunnya kesadaran masyarakat hingga masjid menjadi makmur bukan hanya fisiknya namun jamaahnya secara kualitas dan kuantitas bertambah. Hal demikian tidak terlepas dari kinerja dari para pengurus Masjid (BTM) dan dari jamaah masjid AshShiddiiqi yang mendukung pembangunan masjid secara fisik baik struktur bangunannya dan sarana prasarana maupun pengembangan SDM nya melalui pengembangan pendidikan Islam, eksisnya Masjid Ash-Shiddiiqi ditengah hiruppikuk perkotaan. Meskipun demikian pasti dalam dinamikan pengurus masjid mengalami kehambatan atau masalah dalam menjalankan program-program tersebut yakni berupa kesibukan dari para jamaahnya sebagai pekerja diperkotaan. Selain dari itu murid yang sudah duduk dibangku kelas 3 SD sulit untuk mengikuti pengajian di TPA karena harus mengikuti Full Day School. 


\section{DAFTAR PUSTAKA}

Admin. "Sejarah Masjid." https://masjid ashshiddiiqi.wo rdpress.com/se jarah/\# more-3. (accessed January 1, 2020).

Arifin, H. M. Filsafat Pendidikan Islam. Jakarta: Bumi Aksara, 1994.

Ayub, Moh. E. Manajemen Masjid: Petunjuk Praktis Bagi Para Pengurus. Jakarta: Gema Insani Press, 1996.

Budiyanti, M. Reaktualisasi Khittoh Perjuangan Ustadz-Ustadzah TKA-TPA Dalam Gerakan Dakwah Dan Pendidikan Al-Qur'an Di Indonesia. Yogyakarta: BADKO TKA-TPA Kab Bantul, 2006.

Dalmeri, Dalmeri. "Revitalisasi Fungsi Masjid Sebagai Pusat Ekonomi dan Dakwah Multikultural.” Walisongo: Jurnal Penelitian Sosial Keagamaan 22, no. 2 (December 15, 2014): 321-350, http://journal.w alisongo.ac.id/ind ex.php/walisongo/article/view/269 (accessed January 1, 2020).

Departemen Pendidikan Nasional. Kamus Besar Bahasa Indonesia. Jakarta: Pusat Bahasa, 2008.

Gazalba, Sidi. Mesjid Pusat Ibadah Dan Kebudayaan. Jakarta: Pustaka Antara, 1962.

Hasan, M. Ali. Tuntutan Akhlak. Jakarta: Bulan Bintang, 1983.

Husniah. "Peranan Mesjid Dalam Pembinaan Pendidikan Agama Islam Generasi Muda Di Kecamatan Langsa Barat." Prosiding Seminar Nasional Tahunan Fakultas Ilmu Sosial Universitas Negeri Medan Tahun 2017 1, no. 1 (2017): 213-215, $\quad$ http://semnastafis.unimed.ac.id/wpcontent/uploads/2017/11/09.-husniah-Edit.pdf (accessed January 1, 2020).

Ikhwan, Afiful. "Optimalisasi Peran Masjid Dalam Pendidikan Anak: Perspektif Makro Dan Mikro." Edukasi 1, no. 1 (June 2013): 1-16, http://ejournal.staim-

tulungagung.ac.id/index.php/EDUKASI/article/view/110 （accessed January 1, 2020).

Iqbalillah, Muhammad. "Peran Masjid Agung Jami' Malang Dalam Pembinaan Agama Islam Anak Yatim Piatu Non-Panti Kota Malang Melalui Madrasah Diniyah Abul Yatama." Skipsi, Fakultas Ilmu Tarbiyah dan Keguruan UIN Maulana Malik Ibrahim Malang, 2014. http://etheses.uinmalang.ac.id/5017/ (accessed January 1, 2020).

Kurniawan, Harry. Karya Desain Masjid Ash-Shiddiqqi Yogyakarta, 2015.

Madjid, Abdul. Pendidikan Agama Islam Berbasis Kompetensi: Konsep Dan Implementasi Kurikulum 2004. Bandung: PT Remaja Rosadakarya, 2005.

Madjid, Nurkholish. Masyarakat Membumikan Nilai-Nilai Islam Dalam Kehidupan Masyaraskat. Jakarta: Paramadina, 2004.

Nata, Abuddin. Pendidikan Dalam Perspektif Al-Qur'an. Jakarta: Kencana, 2016. 
Nurjannah, Siti. Peranan TKA-TPA Dalam Membentuk Keluarga Sakinah Dalam Buletin GEMA Edisi I. Yogyakarta: BADKO TKA-TPA Propinsi DIY, 1997.

Putra, Ahmad, and Prasetio Rumondor. "Eksistensi Masjid Di Era Rasulullah Dan Era Millenial.” TASÂMUH 17, no. 1 (December 31, 2019): 245-264, https://journal.uinmataram.ac.id/index.php/tasamuh/article/view/1218 (accessed January 1, 2020).

Ramdlani, Subhan. "Kedudukan Dan Fungsi Masjid Agung Terhadap Alun-Alun Kota Malang." Journal of Islamic Architecture 1, no. 1 (March 29, 2010): 8-15, http://ejournal.uin-malang.ac.id/index.php/JIA/article/view/1711 (accessed January 1, 2020).

Ridha, M. Rasyid, and Amirullah Amirullah. "Eksistensi Masjid Makmur Melayu Dalam Syiar Islam Di Kota Makassar (1943-2015).” Seminar Nasional LP2M UNM 2, no. 1 (October 7, 2017): 457-461, https://ojs.unm.ac.id/semnaslemlit/article/view/4063 (accessed January 1, 2020).

Rumondor, Prasetio, and Puspasari M. Y. Gobel. "Pola Pembinaan Kepribadian dan Keagamaan Remaja Masjid Al-Fatah Di Kelurahan Girian Indah Kecamatan Girian Kota Bitung." Al-Izzah: Jurnal Hasil-Hasil Penelitian 14, no. 2 (December 14, 2019): 1-16, http://ejournal.iainkendari.ac.id/alizzah/article/view/1525 (accessed January 1, 2020).

Rusn, Abidin Ibnu. Pemikiran Al-Ghazali Tentang Pendidikan. Yogyakarta: Pustaka Pelajar, 2009.

Supardi, and Teuku Amiruddin. Supardi Dan Teuku Amiruddin, Manajemen Masjid Dalam Pembangunan Masyarakat Optimalisasi Perdan Dan Fungsi Masjid. Yogyakarta: UII Press, 2001.

Yin, Robert K. Qualitative Research from Start to Finish. London: The Guilford Press, 2011. 